\title{
Fragilidade da Vida e Desenvolvimento das Ciências Sociais no Campo da Saúde
}

CLAUDINE HERZLICH*

\section{RESUMO}

A fragilidade da vida humana e a fragilidade da vida social e coletiva são os objetos históricos da medicina e das ciências sociais, respectivamente. Este artigo examina as articulações entre esses dois aspectos da fragilidade da vida, através das relações entre ciências sociais, medicina e saúde pública, em seu histórico de ocasional cooperação mas também de confrontamento e ignorância recíproca, com base em casos históricos - especificamente franceses, ingleses e americanos. Enquanto que na medicina se observa interesse precoce pelos aspectos sociais do adoecer - mesmo que sem maiores consequiências a longo prazo - nas ciências sociais, exceção feita a Mauss, só após a Segunda Guerra Mundial surgem estudos sistemáticos sobre a saúde, em parte vinculados à implantação de sistemas de proteção social em muitos países no pós-guerra. Em uma conjuntura posterior, de retração econômica e forte crítica social, já na década de setenta do século passado, desenvolve-se na França a sociologia da saúde, dando porém preeminência ao "mercado da saúde" e relegando a reflexão sobre a fragilidade da vida a um plano secundário. Mais recentemente, ao final do último século, a epidemiologia social é resgatada do limbo, enfocando mais uma vez a fragilidade da vida como a um tempo corporal e social, buscando maior aproximação com as ciências sociais. Estas têm uma contribuição fundamental para o campo da saúde pública, analisando sistemas de cuidados médicos e o acesso aos mesmos, o impacto social da fragilidade corporal ou ainda o sentido atribuído pelos indivíduos à experiência da doença. É, por fim, sobretudo na identificação de problemas sociais ligados à saúde de pessoas e populações, demandando ação política, que a contribuição das ciências sociais é fundamental.

Palavras-chave: Fragilidade da vida; ciências sociais; saúde pública.

Recebido em: 22/09/2005.

Aprovado em: 10/10/2005. 
A fragilidade corporal e individual da vida humana, a doença e a morte constituem o próprio objeto da medicina. Por sua vez, as ciências sociais, a partir de seu nascimento no século XIX, incluíram entre seus interesses essenciais a fragilidade da vida social e coletiva: de sua organização, de seus sistemas de valores e de suas regulações. A anomia, segundo Durkheim, é característica das instituições e do funcionamento das sociedades modernas. Quais são os elos entre essas duas facetas da "fragilidade da vida"?

Para compreender como eles foram percebidos e analisados, convém retraçar as relações entre as ciências sociais, a medicina e a saúde pública, sua cooperação por vezes, mas também sua confrontação ou sua ignorância recíproca. Tentaremos esboçá-lo, apoiando-nos sobretudo nos casos franceses, ingleses e americanos.

Foram os médicos os primeiros a se interessarem por essa questão: eles enunciaram um discurso sobre o social antes da constituição das ciências sociais. A partir do final do século XVIII, na França, Cabanis sustenta o projeto de uma ciência do homem que vai da psicologia à moral. No século XIX, os higienistas, como Villermé, fazem investigações que prefiguram os trabalhos da sociologia empírica. Eles estudam os elos entre a pobreza, em particular aquela que é engendrada pela industrialização e a urbanização, e a saúde. Eles também reivindicam um papel político para a medicina. Em 1829, o primeiro número da revista Annales d'hygiène publique et de médecine légale (Anais de higiene pública e de medicina legal) proclama: "A medicina não tem unicamente por objeto estudar e curar as doenças; ela tem relações estreitas com a organização social. Por vezes ela ajuda o legislador na elaboração das leis; amiúde ela esclarece o magistrado no tocante à sua aplicação".

Esse movimento não é apenas francês: conhecemos, na Inglaterra, os nomes de Philipp Kay, Gaskell e, sobretudo, Chadwick. Na Alemanha, o nome que predomina é o de Rudolph Virchow, biólogo, médico, higienista e futuro ministro da Prússia, para quem a medicina é antes de tudo uma ciência social. Seu estudo, em 1848, sobre as causas sociais da epidemia de tifo na Alta Silésia, é exemplar. Para ele, não restam dúvidas de que a epidemia é resultante da falta de desenvolvimento e da miséria dessa província. Ele também escreve:

"a história das epidemias é um capítulo capital da história geral da humanidade. As epidemias nada mais são do que grandes advertências, elas dizem ao verdadeiro homem de Estado que, na vida de seus administrados, ocorreu um distúrbio que não pode continuar a ser ignorado, sequer por uma política indolente" (DUBOS, 1973, p. 367). 
Nos Estados Unidos podemos citar, dentre os primeiros especialistas em saúde pública, na primeira metade do século XX, o nome de Sydenstricker, que faz parte do Comitê Ogburn, impulsionado pelo presidente Hoover e cujo objetivo é descrever as social trends da sociedade americana. Sydenstricker escreve em 1933: "Human life in this country is wasted quite as recklessly and continuously, quite as surely in times of peace as in war" (BLOOM, 2002, p. 59). Ele acredita que a ciência pode ser diretamente aplicada aos problemas sociais e mantém contatos estreitos com o Estado. Ele também é favorável à criação de um sistema nacional de seguro-doença (que até hoje não existe nos Estados Unidos). Na mesma época, na França, os médicos, igualmente convencidos de que existe uma relação estreita entre a preocupação sanitária, o conhecimento social e a ação política, também tentam uma aliança com a política. Em 1913, o senador Paul Strauss declara: "a higiene social [...] é, em todo o vigor da palavra, uma parte da arte de administrar e de governar". Ele também escreve: "se fosse necessário passar em revista todos os meios de defesa contra a tuberculose, haveria que se percorrer todo o campo da sociologia" (MURAD; ZYLBERMAN, 1996, p. 118).

No entanto, esses primeiros desenvolvimentos foram frágeis. Muitas iniciativas não tiveram seguimento. Trabalhos importantes tiveram pouca repercussão ou logo caíram no esquecimento. Ao longo de toda essa época, a saúde pública custa a se constituir como disciplina autônoma e é alvo de ataques de outros setores do mundo médico e científico. Como por exemplo, na Alemanha, em 1893, quando Émile Behring critica Virchow e considera que, a partir das descobertas de Pasteur e de Koch, não se deve mais "se deixar desviar por considerações sociais" (BLOOM, 2002, p. 20). Por outro lado, mesmo se os higienistas gostam de se considerar sociólogos, e afirmam de bom grado que a medicina é uma ciência social, os laços entre a saúde pública ou a medicina social e as ciências sociais em desenvolvimento, em particular a sociologia, permaneceram frouxos, limitados a alguns casos exemplares.

Com efeito, durante muito tempo a sociologia ignorou esse domínio. Desde o início ela se interessou pelo trabalho, pela educação, pela família, pelas religiões, mas as realidades do corpo, da doença e da saúde lhe pareceram estar fora do campo social, com exceção de Marcel Mauss, que, ao escolher como objeto as "técnicas do corpo", delineou claramente um novo programa de estudos. Durkheim, em compensação, embora saibamos a importância que têm para ele as noções de normal e de patológico e conheçamos seu gosto pelas metáforas orgânicas, pretendeu construir os fatos sociais separadamente dos 
fatos psíquicos e dos fenômenos naturais. Não se deve, portanto, buscar em seu estudo sobre o suicídio, como algumas pessoas o fazem atualmente, a prova de um interesse pela saúde. Na nossa opinião, considerar Le suicide uma obra pioneira de epidemiologia psiquiátrica é um erro relacionado ao modo como concebemos a saúde nos dias de hoje. Ao tomá-lo por objeto, Durkheim estudava um ato de violência que acarreta a morte (mas nem todas as mortes são causadas por problemas de saúde). Ele desejava salientar seu caráter puramente social, ligado particularmente à estrutura familiar, enquanto que o senso comum o concebia então como um ato puramente individual.

O interesse dos sociólogos pela saúde só vem a surgir durante as décadas que sucedem a Segunda Guerra Mundial. Nessa época, os progressos da medicina, em particular a descoberta dos antibióticos, suscitam muitas esperanças. Paralelamente, a instauração de sistemas de proteção social em muitos países faz da saúde um dos principais objetivos das sociedades do pósguerra. Assistimos então a uma proliferação inédita dos serviços médicos. Ao refletir sobre essa evolução, Talcott Parsons analisou, nos Estados Unidos, em 1951, as significações sociais da saúde, assim como a função de regulação social da medicina para além de sua função técnica: ele quer compreender o papel "societal" de uma instituição que vivencia um tal desenvolvimento. Sua análise se insere em seu esforço de compreensão geral das formas da ação e das condições de manutenção da ordem social.

O novo interesse por esse campo corresponde, portanto, por um lado, a interesses históricos dos sociólogos mas, por outro, ele se ancora na tomada de consciência de uma evolução fundamental da sociedade: sua "medicalização". Ainda mais porque, nessa mesma época, nos Estados Unidos e na Inglaterra, surge uma demanda de pesquisa acompanhada por propostas de financiamento. Na Inglaterra, ela emana do Estado e está ligada à criação do National Health Service, ao desejo de otimizar sua eficácia e sua eqüidade: percebeu-se rapidamente que ele beneficiava mais as classes médias do que as populares. Nos Estados Unidos a impulsão provém do meio médico, das escolas de medicina e das grandes fundações preocupadas com a heterogeneidade extrema dos serviços de saúde e com as desigualdades consideráveis de acesso aos cuidados médicos por parte dos diferentes grupos sociais e étnicos. Porém, além de algumas vozes discordantes, ninguém considera a criação de um seguro-doença generalizado ou a possibilidade de se fazer reformas estruturais.

Considera-se que a solução para esses problemas deve surgir do livre desenvolvimento do mercado de serviços médicos O que se espera das ciências 
sociais, primeiramente, é que elas contribuam, através de sua presença nas escolas de medicina, à formação de um médico "socialmente orientado"; em seguida, que elas analisem os "obstáculos culturais", sendo que as "crenças" irracionais constituem um obstáculo ao desenvolvimento desses serviços. A partir dessas bases irão se desenvolver, nos anos sessenta, os grandes estudos sobre "o estudante de medicina", assim como a corrente "Health Services Research", voltada para o gerenciamento dos sistemas de cuidados médicos, a observância dos pacientes e a adesão do público às campanhas de prevenção.

Os caminhos que levam da sociedade às ciências sociais, as expectativas em relação a estas, o posicionamento político das pesquisas não são os mesmos na Inglaterra e nos Estados Unidos. O caso francês é ainda diferente. A partir de 1945, em parte devido às esperanças geradas pelos progressos terapêuticos, a França adentra um período totalmente voltado para a medicina. O número de médicos praticamente dobrou entre 1945 e 1960, e um consenso une a opinião e a classe política: "a saúde não tem preço". Ao criar a segurança social, após a guerra, o Estado assumiu seu papel "protetor": proporcionou os meios financeiros para um acesso generalizado aos cuidados médicos.

O "modelo francês" é então considerado uma síntese harmoniosa entre as vantagens da medicina liberal, que garante a livre escolha do médico pelo paciente, e aquelas ligadas à garantia da cobertura financeira do tratamento. Dessa forma, os poderes públicos se retraem diante da medicina, conferindolhe o campo da saúde. Porém, como a ameaça coletiva das doenças transmissíveis se amenizou, os médicos deixaram de ser higienistas e de se interessar pelo aspecto social. Em tal contexto, durante mais de duas décadas a saúde pública torna-se uma disciplina enfraquecida, dominada pela medicina clínica, e nem os poderes públicos, nem o corpo médico, nem a opinião pública se interrogam sobre uma saúde que exigisse a atenção das ciências sociais.

Tudo vai mudar durante os anos setenta. A saúde passa a ser um dos campos em que se manifesta mais fortemente a tendência crítica que, a partir do movimento de Maio de 68, atinge toda a vida social. O "poder médico" é um de seus principais alvos. As denúncias que lhe são dirigidas põem em causa a sociedade capitalista e oferecem perspectivas de análise a sociólogos freqüentemente marcados pela influência marxista. Por outro lado, em 1974, o crescimento econômico se interrompe na Europa. Nesse contexto mais difícil, tem início na França um debate político-administrativo sobre os custos da saúde, a necessidade de otimizar os recursos financeiros e a exigência de uma gestão 
racional dos serviços médicos. Assim como ocorrera quinze anos antes nos países anglo-saxônicos, essas interrogações levam a uma demanda de pesquisas. Dessa forma, num contexto de forte expansão das ciências sociais durante os anos setenta e oitenta, desenvolve-se na França um novo campo de pesquisas: a "sociologia da saúde".

Convém ressaltar que, no contexto de desenvolvimento dos serviços médicos, o "mercado da saúde" constituía o objeto central da pesquisa. Assim, a questão da fragilidade da vida corporal e a participação do social nessa fragilidade perderam a importância que tiveram no século XIX e nas primeiras décadas do século XX. Como se esperava da abordagem médica que ela resolvesse tudo, a análise dos determinantes sociais da saúde e das desigualdades sociais diante da saúde foi de certa forma negligenciada pela saúde pública e pela epidemiologia. No estudo desenvolvido durante os anos sessenta, sobre os fatores de risco de diversas patologias (estudo das relações entre o consumo de tabaco e o câncer do pulmão, por exemplo), as variáveis ligadas às classes sociais foram consideradas secundárias.

Mas as ciências sociais também não se dedicaram muito a essa questão. Com exceção talvez da Inglaterra, onde a tradição dos estudos sobre a saúde pública da população é antiga e onde a publicidade que lhe é feita e a atenção da esfera política alimentam o interesse dos pesquisadores pelo estudo das desigualdades sociais da saúde. Nos Estados Unidos, em contrapartida, o estudo clássico de Hollingshead e Redlich, Social Class and Mental Illness, publicado em 1957, foi abundantemente comentado e citado, mas não foi mais desenvolvido. Na França, a primeira obra significativa sobre o tema das desigualdades sociais da saúde reunindo estudos de epidemiologia e ciências sociais só foi publicada em 2000 (LECLERC et al., 2000).

Entretanto, nos últimos anos, alguns epidemiologistas resgataram o tema e assiste-se ao desenvolvimento de uma "epidemiologia social" que renova a problemática e enfoca novamente a fragilidade da vida como uma fragilidade ao mesmo tempo corporal e social. A ambição não se limita mais a evidenciar as desigualdades, mas tenta compreender como, segundo a expressão bastante utilizada, "o social atravessa a pele". Os pesquisadores recorrem muitas vezes a conceitos provenientes das ciências sociais, tais como "redes sociais", "suporte social" ou ainda "capital social". Em todos os casos, trata-se de ultrapassar a mera análise da posição dos indivíduos na estrutura social e de melhor apreender o que engloba a própria noção de "social" nos determinantes da saúde. 
Ainda é muito cedo para fazer um balanço definitivo e para avaliar até que ponto esse campo poderá representar um local de cooperação positiva entre as ciências sociais e a saúde pública. Sempre consideramos que o fato de compreender que inscrição o social imprime nos corpos constitui um desafio crucial para a sociologia, e esperamos não hesitar em abordá-lo frontalmente. Porém devemos estar cientes das dificuldades que sempre entravam a colaboração entre nossas disciplinas.

Em primeiro lugar, as ciências sociais quase sempre recorrem a uma abordagem contextual e histórica de um problema: a pobreza na Alta Silésia, que provocou a epidemia de tifo estudada por Virchow em 1848, não é a mesma dos habitantes dos conjuntos de prédios populares dos subúrbios europeus, nem das favelas brasileiras ou dos habitantes dos países do Terceiro Mundo. Temos, portanto, dificuldade para conciliar a historicidade de nossos métodos com a busca de determinações que a epidemiologia tende a considerar independentemente de qualquer referência temporal e contextual.

Isso nos leva a um segundo ponto: embora a epidemiologia esteja longe de raciocinar em termos de causalidade estrita, seus modelos de análise encontram-se bastante afastados daqueles da sociologia. Esta última, sobretudo depois do declínio dos grandes paradigmas explicativos do futuro das sociedades, como o marxismo, desconfia cada vez mais das idéias de determinação e de causalidade. A atração exercida por uma noção como a "configuração" evocada por Norbert Elias, por exemplo, provém em grande parte dessa desconfiança. Devido a essas duas razões, será sempre difícil dispor de noções que evidenciem "o social", simples e inequívocas, que possam ser inseridas, sem modificação, nas análises epidemiológicas.

Mas as ciências sociais abordaram outros temas que permitem compreender melhor as diversas modalidades de interação entre as dimensões corporais e sociais da "fragilidade da vida". Os resultados de suas pesquisas podem e devem alimentar a reflexão e a ação na saúde pública. Primeiramente, a análise do sistema de cuidados médicos e de seu funcionamento, realizada por sociólogos e economistas, evidenciou constantemente a importância fundamental das variáveis sociais (nas quais se deve incluir, além da posição na hierarquia social, o nível de educação, a etnia e o gênero). Elas influenciam a própria estruturação dos serviços (por exemplo, ao fundar a distinção públicoprivado cuja importância conhecemos), o acesso das populações (intermediado ou não por um sistema de seguro-doença). Elas se encontram na origem da 
diferenciação dos tipos de clientelas segundo trajetórias distintas para patologias ou condições idênticas. Elas influem sobre a atenção concedida aos pacientes, assim como sobre a eficácia e a qualidade dos serviços.

Em todos os planos, a fragilidade social de uma pessoa, de uma família, de um grupo, de uma população, ou de uma nação, interfere na qualidade da resposta em termos de sua fragilidade corporal, entrava ou altera seu tratamento e sua "reparação". O mesmo ocorre quando se trata de prevenir: o acesso à prevenção está marcado pelas desigualdades sociais. Os numerosos trabalhos sociológicos realizados sob a influência das campanhas de informação e de prevenção demonstraram adequadamente o peso dos recursos e exigências ligados à posição social, e que se opõem à adoção de um "modo de vida saudável" no dia-a-dia. Elas demonstram também que, muitas vezes, as pessoas mais desfavorecidas socialmente, impossibilitadas de adotar um "modo de vida saudável", são aquelas que, paradoxalmente, estão mais convencidas de sua importância para a saúde. A reflexão sobre os sistemas de saúde ou os dispositivos de prevenção, sua qualidade e seu impacto, não pode ignorar essas análises e seus resultados.

Em um plano totalmente diverso, através do estudo L'expérience de la maladie et du handicap (A experiência das doenças e das deficiências), a sociologia evidencia o impacto social da fragilidade corporal e seu peso sobre a vida das pessoas. $\mathrm{O}$ estudo minucioso da vida cotidiana com uma doença crônica demonstra na maior parte das vezes uma desestabilização irreversível: a ruptura das rotinas cotidianas, a necessidade de reavaliar os comportamentos habituais, os "conhecimentos da experiência" em que está assente a existência pessoal de cada um, notadamente da vida em família e no trabalho. Ao estudar essas diversas desorganizações, os pesquisadores efetuam uma análise aprofundada da ordem social cotidiana, de sua fragilidade em relação às exigências corporais e biológicas, das dificuldades de sua reorganização. Através dessas análises, abre-se espaço nessas disciplinas para os estados do corpo, durante muito tempo negligenciados pelas ciências sociais. Em contrapartida, essas disciplinas podem assim contribuir para modificar a perspectiva que os profissionais da saúde têm dos estados corporais, suas disfunções e sua fragilidade.

Da mesma forma, a análise do sentido atribuído à experiência da doença pelas pessoas que se confrontam com ela demonstra claramente a importância das dimensões corporais da identidade. Os pesquisadores relacionaram o conjunto 
dos avatares da auto-estima acarretados por uma doença crônica e suas conseqüências sobre todas as relações sociais: o sentimento de "vergonha" ligado às degradações do corpo, de "stigmates ressentis" no contato com outras pessoas, e até a impressão de "perda de si" sentida com frequiência pelos doentes. Michael Bury propôs a noção de "ruptura biográfica" (BURY, 1982) para manifestar, em sua dimensão temporal, o conjunto dos efeitos da fragilidade corporal sobre a identidade de uma pessoa.

Finalmente, convém também considerar a contribuição das ciências sociais em um plano macrossocial. Elas revelaram a importância dos desafios associados ao valor-saúde nas sociedades de hoje; elas demonstraram a expansão de sua presença no espaço público e no debate político e analisaram a extensão de sua dimensão simbólica.

$\mathrm{O}$ resultado mais importante do primeiro estudo que realizamos, nos anos sessenta, sobre as representações coletivas da doença e da saúde (HERZLICH, 1969), foi que as pessoas interrogadas estabeleciam um paralelo e uma relação de sentido entre sua fragilidade corporal individual e as disfunções e exigências da sociedade moderna. Hoje, essa dimensão simbólica se transferiu para o plano coletivo e político. Cada vez mais, a sociedade fala a si própria em termos de saúde. Diversos autores ${ }^{1}$ salientaram que, muitas vezes, a referência à saúde é a única a legitimar o aparecimento no espaço público de um problema social, até então ocultado ou denegado, e ela possibilita o surgimento de um debate coletivo. Assim durante o verão de 2003, na França, os efeitos de uma onda de calor excepcional sobre a saúde das pessoas idosas subitamente tornaram visíveis as dificuldades de sua situação, suscitando acalorado debate sobre o status da velhice na sociedade francesa.

A apreensão de um problema social em termos de saúde ameaçada, de fragilidade corporal (a irrupção de uma patologia, o aparecimento de um risco) autoriza a ação política, e inclusive a torna necessária e urgente. Da mesma forma, o "escândalo" nesse contexto (como, na França, o escândalo do "sangue contaminado" pelo vírus da AIDS, nos anos 90) parece simbolizar, mais do que qualquer outro problema, a degradação da vida coletiva e a falência de suas regulações. É nesse contexto, em que a saúde tem o estatuto de principal referente simbólico, que qualquer ação de saúde pública deve doravante se situar. Para compreender suas implicações, a contribuição das ciências sociais é indispensável. 


\section{Referências}

BLOOM, S. The Word as Scalpel: a history of medical sociology. New York: Oxford University Press, 2002.

BURY, M. Chronic Illness as Biographical Disruption. Sociology of Health and Illness, v. 4, n. 2, p.167-82, 1982.

DUBOS, R. L'homme et l'adaptation au milieu. Paris: Payot, 1973.

FASSIN, D. Les figures urbaines de la santé publique. Paris: La Découverte, 1998.

HERZLICH, C. Médecine moderne et quête de sens: la maladie signifiant social. In: M. AUGÉ, M.; HERZLICH, C. Le sens du mal. Paris: Archives Contemporaines, 1983. p. 189-215.

HERZLICH, C. Santé et maladie, analyse d'une représentation sociale. Paris: Mouton, 1969.

LECLERC, A. et al. Les inégalités sociales de santé. Paris: La Découverte, 2000.

MURARD, L.; ZYLBERMAN, P. l'hygiène dans la Republique. Paris: Fayard, 1996.

\section{NOTAS}

* Socióloga, Centre de Recherche Médecine, Maladie et Sciences Sociales (CERMES), França. Endereço eletrônico: herzlich@vjf.cnrs.fr.

${ }^{1}$ Expressamos a idéia da doença como "significante social” em Herzlich (1983). Ver também Fassin (1998). 


\section{ABSTRACT}

\section{Frailty of life and development of Social Sciences in the Field of Health}

The frailty of the human life and the frailty of the social and collective lives are the historical objects of medicine and the social sciences, respectively. This paper examines the connections between those two aspects of the frailty of life, through the relationships between the social sciences, medicine and public health, in their history of occasional cooperational but also of confrontation and mutual ignorance, based on historical cases - namely, French, English and American. Whereas in medicine there was an early interest on the social aspects of diseases - even though it had no lasting consequences - in the social sciences, Mauss excepted, it is only after the second world war that systematic studies about health are produced, partly linked to the establishment of systems of social protection in many countries in the aftermath of the war. In a later conjuncture, of economical retraction and strong social criticism, in last century's seventies, the sociology of health is developed in France, giving prominence to the "health market" and relegating the reflection on the frailty of life to a secondary plane. More recently, at the end of the last century, social epidemiology was rescued from the limbo, once more focusing the frailty of life as both a corporal and social issue, reaching for a closer cooperation with the social sciences. The latter have a key contribution to public health, analyzing health care systems and the access to them, the social impact of the frailty of the body or the meaning attributed by individuals experiencing it as well. It is, finally, foremost in identifying social problems linked with the health of individuals and populations, demanding in turn political action, that the contribution of the social sciences is fundamental.

Key words: Frailty of life; social sciences; public health. 